https://dx.doi.org/10.4314/ijs.v20i1.2

Ife Journal of Science vol. 20, no. 1 (2018)

\title{
ROCK TYPE BASED POROPERM AND CONTINUOUS PERMEABILITY PREDICTIONS IN A TIGHT GAS FORMATION.
}

\author{
Ojo, S.A. ${ }^{1,2}$, Olatinsu, O.B. ${ }^{1}$, Ozebo, V.C. ${ }^{1}$ \\ ${ }^{1}$ Department of Physics (Geophysics Unit), University of Lagos, Nigeria. \\ ${ }^{2}$ Initially with Institute of Applied Geoscience, University of Leeds, United Kingdom. \\ Email:ojoakinjidesamuel@gmail.com, Tel: 07033383932 \\ (Received: $12^{\text {th }}$ September, 2017; Accepted: $16^{\text {th }}$ November, 2017)
}

\section{ABSTRACT}

\begin{abstract}
Porosity from log response such as density provides a continuous representation of pore volume as function of depth in a well, which can be calibrated with core analysis data. Obtaining a continuous log of permeability is not as straightforward as there is yet no means of logging permeability. While DST-derived permeability values are useful in calibrating dynamic models, they only represent an average value over the radius investigated by the test and will not readily correlate to permeability values derived from core especially where there are lateral and vertical permeability variations within the reservoir. It is, however, possible to obtain a depth-continuous permeability estimate by deriving a free regression algorithm known as the poroperm transform function, which defines how the permeability varies as a function of porosity. Such correlations are typically derived empirically from overburden corrected core-derived porosity and permeability data. General porosity-permeability trends are far too scattered to be of use. However, far tighter porosity-permeability trends can be obtained by use of rock typing to identify suitable analogues. The following study highlights how microstructural rock-tying can be used to improve permeability prediction in a set of tight gas sandstone wells. Scanning electron microscopy $(\mathrm{SEM})$ and quantitative X-ray diffraction (QXRD) data were obtained from $>200$ tight gas sandstone samples from the Southern North Sea for which porosity and permeability measurements had previously been conducted. The SEM and QXRD data were used to derive microstructural and mineralogical rock types respectively. Samples from each rock-types occupy different but overlapping positions on porosity-permeability cross plots. Exponential functions were fitted to porosity-permeability data for each rock type and then applied to the porosity values from wire-line log data to derive continuous permeability estimates. The log porosity curves-being the independent variables of the respective functions, were validated by core observation to avoid error propagation. Continuous permeability curves that honour mineralogical variation were obtained by the use of microstructural rock typing.
\end{abstract}

Key words: Porosity, Permeability, Rock-typing, Poroperm, Microstructural, Mineralogical.

\section{INTRODUCTION}

\section{Continuous permeability}

Permeability is a reservoir property that cannot be over studied in the field of petroleum geosciences especially in this petroleum age, where principal attention is on production characteristics of petroleum reservoirs as against the early focus on observing regional tectonics and local structures (Ali et al., 2010). It is an important component of a typical petroleum system that defines its ability to allow the flow of fluids. If hydrocarbon from the source rock flowing through the migration pathway requires a house (pore space) to stay, there must be a passage (permeability) for it to be extracted via. Core permeabilities, just as most core data, are discontinuous and represent information on a small scale compared to average response of a logging tool (Archer et al.,1986). Depth continuous permeability will be a more useful data set for computing hydrocarbon flow rate based on the radial flow equations. Obtaining a continuous $\log$ of permeability is not straightforward as there is yet no technique for logging permeability. In spite of this short coming, the petroleum industries desire a depth-continuous permeability curve and besides, not all wells are cored due to the high costs of coring and laboratory measurements.

Since most wells are logged, the popular practice is to estimate permeability from logs using correlation equations developed from limited core data(Xie, 2008)

Different petroleum companies have attempted different ways of predicting continuous permeability in wells. Individual companies tend to stick to the approach that works best per owned oil field. There is however a common practice, which is to validate the predicted permeability with the existing core permeability values. A statistical approach is to find an empirical 
correlation between core permeability and core porosity in order to derive a transform function, which is then applied to the porosity values from wire-line $\log$ data to derive continuous permeability estimates.

If the reservoir of interest is homogeneous, with similar pore network geometry, the permeability predictions via this approach may be error free even with a single function fitted for the entire reservoir. However, prediction inaccuracies are often large in typical sandstones, and the errors in predicted permeability commonly range across orders of magnitude. The reason for this is that permeability is not exclusively determined by pore volume, but is also controlled by other variables such as network channel tortuosity, pore throat geometry etc., hence the need for rock typing. Permeability prediction for reservoir characterization relies on understanding the factors that control reservoir heterogeneity. (Teh et al., 2012)

A rock typing technique, not carefully selected could be another source of error in poroperm linear regression analysis. Permeability controls are clues to what rock typing technique should be applied to discriminate rock samples into different rock types. In this study, the authigenic clay morphology (grain coating and pore filling) appear to have an excellent relationship with pore network geometry hence control how the samples' permeability varies as a function of porosity. On this basis, the studied samples were classified according to microstructural variation. Discriminating a reservoir using different rock typing techniques has resulted in deriving several poroperm functions which were applied to generate different permeability curves from wireline $\log$ data. The disparity observed between versions of predicted permeability curves, necessitated quality checking each technique by comparing its predicted permeability curve with the Klinkenberg and stress corrected core permeability range.

\section{Porosity from $\log$ response}

According to Worthington (2011), most petrophysical parameters are hardly ever measured directly down hole but are instead inferred from measurable physical properties, so the discipline of petrophysics is built around a frame work of interpretive algorithms converting physical quantities to reservoir parameters. Log derived porosity is a reservoir parameter though not measured in situ but can be estimated from density $\log$ response $\left(\rho_{\mathrm{b}}\right)$ through the below algorithm:

$\phi=\frac{\rho_{m a}-\rho_{b}}{\rho_{m a}-\rho_{f}}$

Where $\rho_{m a}$ refers to the matrix density and $\rho_{f}$ refers to density of the fluid saturating the pore investigated by the density tool. Log-derived porosity is depth continuous and can be validated by core porosity values.

\section{Diagenesis and reservoir quality.}

Diagenesis comprises all processes that convert raw sediment to sedimentary rock (Ali et al., 2010). Sediments, once buried, undergo a series of alterations to maintain in equilibrium with environment as burial depth increases. This formation of new minerals and modification of existing ones could produce changes in clay morphology. The different clay morphologies affect sandstones porosity and permeability differently (Neasham et al., 1977). The detrital illite occurs as grain lining, tangentially arranged, ragged plates while authigenic illite (formed through diagenesis) occurs as pore filling, feldspar replacing, kaolinite transitional and grain coating(Huang, 2012).

The reaction of $\mathrm{K}$-feldspar + kaolin to form illite is temperature dependent so could be influenced by the degree of burial (Huang, 2012).More so, the combine presence of secondary (dissolution) porosity and pore filling authigenic illite suggests that $\mathrm{K}$-feldspar reaction occurs during burial diagenesis (Huang, 2012). A relationship does exist between digenesis and prevailing reservoir quality index. Deep reservoir quality in sandstones is the cumulative product of depositional, shallow digenetic, and deep-burial digenetic processes (Joanna M. and Lander, 2010).

Permeability for instance is very sensitive to changes in overburden pressure or to digenetic alterations (Walder and Nur, 1984; Walsh and Brace, 1984; Leder and Park, 1986). 
Authigenic clay minerals are formed within the pore space during diagenesis and usually affect reservoir qualities (McPhee, Reed and Zubizarreta, 2015). The impact they have on the production characteristics of the reservoir overshadows the percentage distribution they occupy in the reservoir pore system (McPhee et. al., 2015).The formation of authigenic illite from smectite takes place by solid transformation that occurred gradually and progressively in response to increasing temperature and depth (Eberl, 1993). A method of using gamma ray log (a lithology log) as a reservoir quality indicator may be unreliable especially for formations that have undergone a number of digenetic changes and yet reflect a relatively constant radioactive content. However, if the original pore space is not altered too much, then a relationship exists between lithofacies and reservoir quality (Walder and Nur, 1984; Walsh and Brace, 1984; Leder and Park, 1986). The essence for deliberate focus on diagenesis is these days quest for reservoir quality (Ali et. al., 2010)

\section{MATERIALS AND METHODS}

\section{Data and software used}

Core data were obtained from approximately two hundred (200) tight gas sandstone samples. These data include: (i) Scanning electron microscopy (SEM) and quantitative X-ray diffraction (QXRD) data (ii) Core porosity data measured at ambient condition (iii) core permeability data measured at simulated net confining stress. The samples were mainly dominated by quartz, illite and kaolin with a few carbonate minerals such as siderite. Log data (Gamma ray log, neutron porosity log and density $\log$ ) from two wells were available.

Interactive Petrophysics software (version 4.2) was used to interpret the log data obtained.

\section{Core porosity measurement}

The porosity measurements of most of core plugs were taken prior to this study. However, few other core plugs were measured using a similar methodology which is the combination of a twincell helium porosimeter and calliper for grain volume and bulk volume determination respectively.

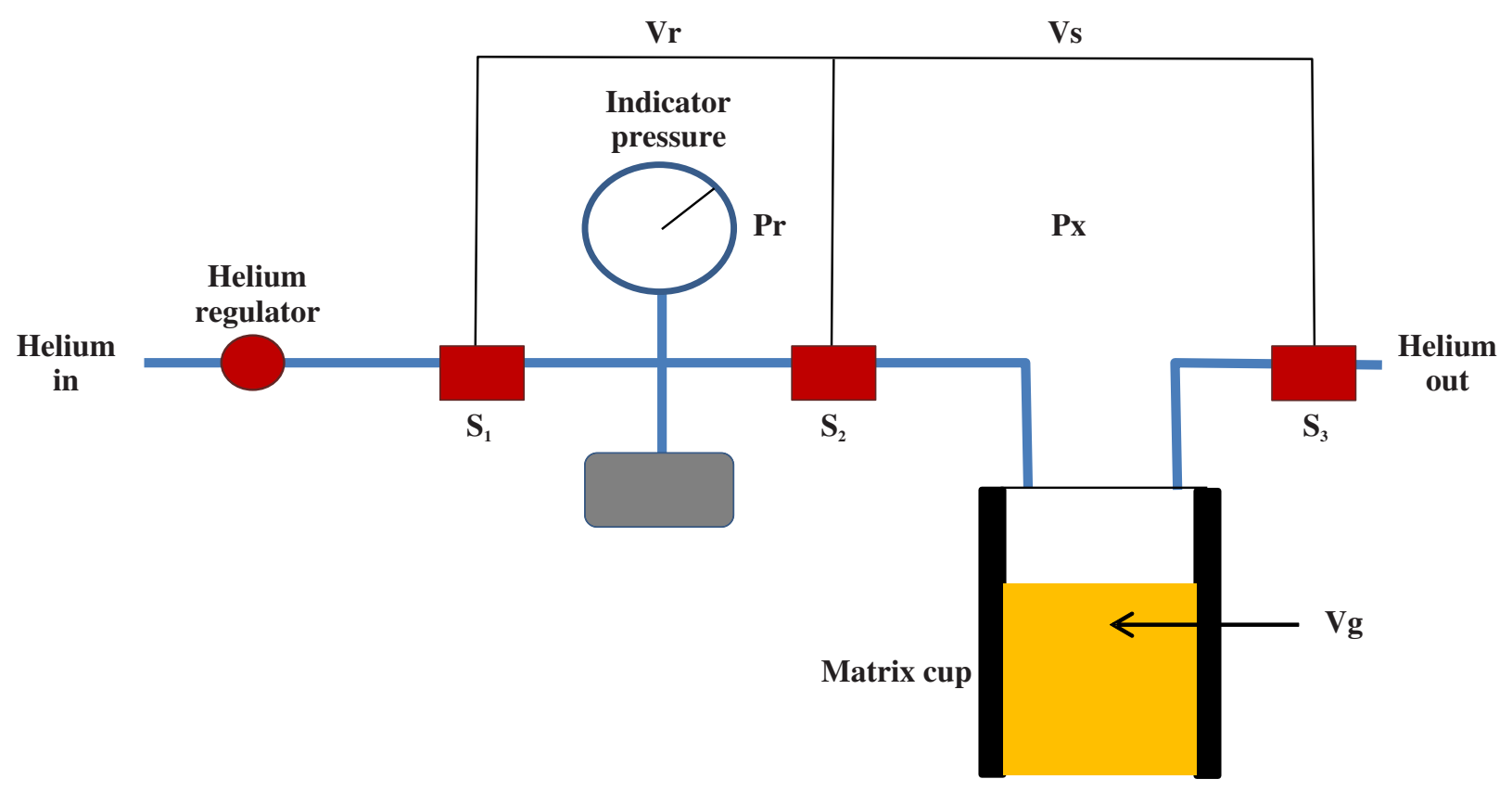

Figure 1. Helium grain volume instrument schematic (matrix cup filled with plugs) 
This apparatus works with the principle of Boyle's law(i.e. $P_{1} V_{1}=P_{2} V_{2}$ for a closed. system). According to the above schematics, helium is allowed into the reference chamber of volume $V_{r}$ at a pressure $P_{r}$ Valves $S_{1}$ and $S_{2}$ were used to isolate the reference chamber in order to take a steady measurement ofwhile was opened so that the gas at $P_{r}$ in the reference chamber expands to fill both $V_{r}$ and $V_{s}$ where is the volume of the sample chamber that contains the core plug of grain volume $V g$. The final expanded pressure recorded was represented by $P_{x}$ and Boyle's law was rewritten as:

$P_{r} V_{r}=P_{x}\left(V_{r}+V_{s}-V_{g}\right)$

By rearranging Eq. 2 was calculated using:

$V_{g}=\frac{P_{x}\left(V_{r}+V_{s}\right)-P_{r} V_{r}}{P_{x}}$

The instrument was initially calibrated using standard plugs of known grain/bulk volume in order to determine $V_{r}$ and $V_{s}$. The cross-sectional areas of the cylindrical samples were calculated from average diameter $(D)$ and multiplied by the sample length $(L)$ to obtain bulk volume $\left(V_{b}\right)$ while the samples porosities were calculated using:

$\phi=\frac{V_{b}-V_{g}}{V_{b}}$

Grain density was calculated using Eq. 5 in order to verify consistency in lithology and to as well identify lithological anomalies. $M_{s}$ is the mass of the sample.

$\rho_{g}=\frac{M_{s}}{V_{g}}$

\section{Core porosity correction for overburden.}

By assuming a uniaxial correction protocol (UCP), the net confining stress $(N s c)$ was estimated using:

$N c s=T v d(f t) *(1-0.433)$

$T v d$ is the true vertical depth. 1psi/ftwas assumed for lithostatic pressure gradient while $0.433 p s i f f t$ was taken to be the reservoir pore pressure per foot, assuming the reservoir is normal pressured. Porosity was corrected to the estimated net overburden pressure by using the empirical relationships derived by the Discovery Group for the Mesaverde Tight Gas Sandstones from US Basins,(Byrnes, 2009).Eq. 7,8 and 9.

$$
\frac{\phi_{i}}{\phi_{o}}=A \log (N c s)+B
$$

$$
\begin{aligned}
& A=-0.00549-\frac{0.155}{\phi^{0.5}} \\
& B=1.045+\frac{0.128}{\phi}
\end{aligned}
$$

Where $\phi_{i}$ is the porosity at net in situ stress, $\phi_{o}$ is the reference initial porosity.

\section{Permeability measurement and correction for klinkenberg.}

Most of the permeability measurements previously made of the analysed samples were reported to have been taken by pulse decay (unsteady-state) technique. This was probably due to the very low permeability of the measured samples through which the attainment of steadystate conditions can possibly take hours. There were however exception samples(with relatively high permeabilities) that passed for the steady state conditions of which such measurements were made under a simulated reservoir condition ( $\sim 5000$ psi).Gas was used as the flowing phase for the sake of convenience and because gas does not chemically alter the rock.(Byrnes, 1996).However, the measured permeability had to be klinkenberg corrected due to the mean-free path slippage, which is an effect mostly common with gas molecules when flowing through porous media.

Measurements were made at four mean pressures McPhee, Reed and Zubizarreta, 2015). The apparent permeability(i.e. gas permeability)values were plotted against the corresponding inverse mean pressure $\left(P_{m}^{-1}\right)$ values and the plot was extrapolated to the point where $P_{m}^{-1}=0\left(P_{m} \rightarrow \infty\right)$ to take reading of the klinkenberg corrected permeability.

\section{Log porosity calibration.}

The matrix densities $\rho_{m a}$ (referred to as grain densities in core measurements) were retrieved from the measured core data. Thebulk density $\left(\rho_{b}\right)$ was plotted against core porosity $\phi$ for double phase reservoirs (gas and water).Due to the observed gravity segregation of fluid types and the consistency of porosity across contact, it was possible to estimate from the plot, the representative values of $\rho_{f}$ for both gas and water bearing intervals. 
Volume of shale calculation.

The volume of shale (vsh) was calculated from gamma ray $\log \left(G r_{\log }\right)$ using a linear-response vsh model:

$v s h=\frac{G r_{\log }-G r_{\min }}{G r_{\max }-G r_{\min }}$

Where $G r_{\text {min }}$ and $G r_{\max }$ refer to the sand and shale baseline respectively.

RESULTS AND DISCUSSION Porosity calibration parameters

By Rearranging Eq. 1 in terms of bulk density, $\rho_{b}$ then:

$\rho_{b}=-\left(\rho_{m a}-\rho_{f}\right) \phi+\rho_{m a}$

By cross plotting $\rho_{b}$ against $\phi$, the slope is $-\left(\rho_{m a}\right.$ $-\rho_{f}$ ) and the intercept when $\phi=0$ is $\rho_{m a}$ (i.e. the density of the solid framework of the understudied lithology). Therefore the fluid density for each fluid type represented in this field as shown in Fig. 2 was estimated from:

$\rho_{f}=$ slope $+\rho_{\text {ma }}$

Continuous porosity curves were determined using Eq.1 and were validated by core observations.

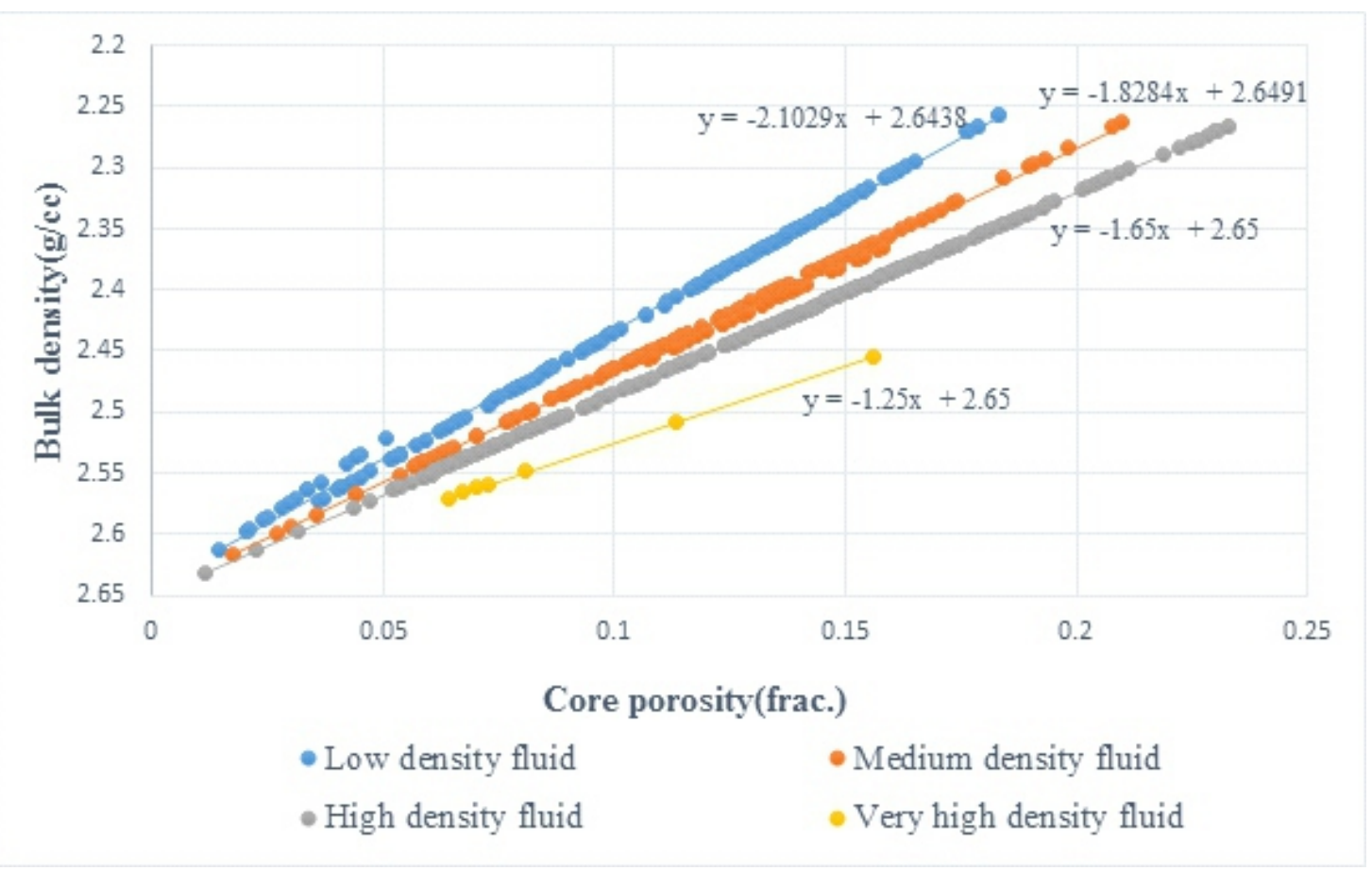

Fig. 2.Fluid density prediction chart.

The matrix density as shown by the four equations generated from the four plots respectively is consistently $2.65 \mathrm{~g} / \mathrm{cc}$ confirming that the studied interval is of uniform lithology. The fluid density is not necessarily the actual formation fluid density. It could be the density of the mixture of mud and formation fluid depending on the degree of invasion.

Table I. Fluid density values.

\begin{tabular}{|l|l|l|l|l|}
\hline Fluid Type & Slope & \multicolumn{1}{|c|}{${ }_{m a}(\mathrm{~g} / \mathrm{cc})$} & $f_{f}(\mathrm{~g} / \mathrm{cc})$ & Fluid Column \\
\hline Low density & -2.10 & 2.65 & 0.55 & Gas \\
\hline Medium density & -1.82 & 2.65 & 0.83 & Gas \\
\hline High density & -1.65 & 2.65 & 1.00 & Water \\
\hline Very high density & -1.25 & 2.65 & 1.40 & Water \\
\hline
\end{tabular}


Since the density logging tools have a shallow depth of investigation, there are therefore three possible factors that could have contributed to the above estimated fluid densities (i) the intrinsic formation fluid density (ii) the mud type/density (iii) the degree of invasion.

Variable fluid densities were observed, even in the gas column. This is likely due to difference in the degree of mud invasion if the intrinsic gas specificgravity is assumed to be constant. The very high fluid density $(1.4 \mathrm{~g} / \mathrm{cc})$ associated with some sections of the water leg is due to the very high salinity of such units. Change in salinity at different depth intervals of a water leg can easily be seen on the deep resistivity log signature.

Due to the unavailability of intrinsic-fluid-property information and invasion resistivity profile logs, it was not possible to attempt building a variable-fluiddensity profile from another source. However, the estimated fluid densities using this approach can be said with a high magnitude of certainty to be that of those probed by the density tool.

\section{Rock-typing and poroperm in a homogeneous reservoir.}

A poroperm cross-plot was obtained for a simple reservoir with relatively constant microstructures. (Fig.3). All data points plotted along a straight-line and showed no significant $\operatorname{scatter}\left(R^{2}=0.87\right)$. The empirically derived function from this plot would generate a reasonable estimate of continuous permeability when applied to $\log$ derived porosity values.

This scenario is however uncommon due to heterogeneity of most reservoirs. Most reservoirs in this study are far from the case in Fig.3

Fig.6d shows a general poroperm cross-plot from overburden corrected core-derived porosity and permeability data. It gives a poroperm trend with some degree of scatter $\left(R^{2}=0.49\right)$. Any attempt to use this derived function will oversimplify the permeability estimate, since the reservoir heterogeneity will not be captured and could therefore have a misleading influence on subsequently estimated properties.

Nevertheless, far tighter porosity-permeability trends were obtained by the use of rock typing (fig.6a, 6b, and 6c).

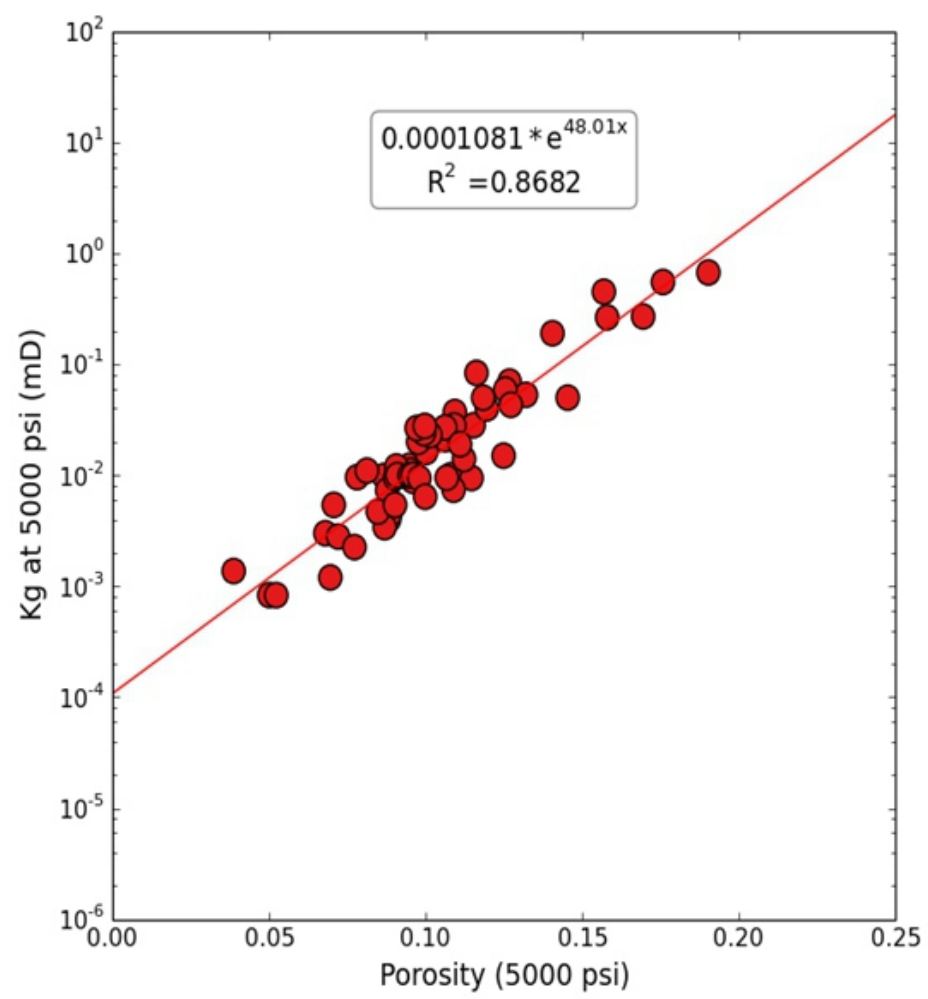

Fig.3. Poroperm cross-plot for a homogenous reservoir 
Authigenic clay mineralogy and morphology. Mineralogy majorly dominated by illite, kaolin and quartz. Two clay morphologies; grain coating and pore filling were identified from SEM analysis. Energy dispersive spectroscopy (EDS) information was used alongside to qualitatively examine the prevailing mineralogy. Kaolin is seen to be scattered within the pore space between quartz grains. (Fig.4a), its grains are relatively bigger compared to the hairy illite, so may not impact reservoir quality as severely, this being contrary to, the filamentous form of illite (Fig.4c) the presence of which has a much greater effect on reservoir qualities. The difference in clay content and morphology formed the basis for grouping the samples into three simple microstructural rock types: (i) clay-free sample; (ii) grain coating clay dominated samples and (iii) porefilling clay samples.

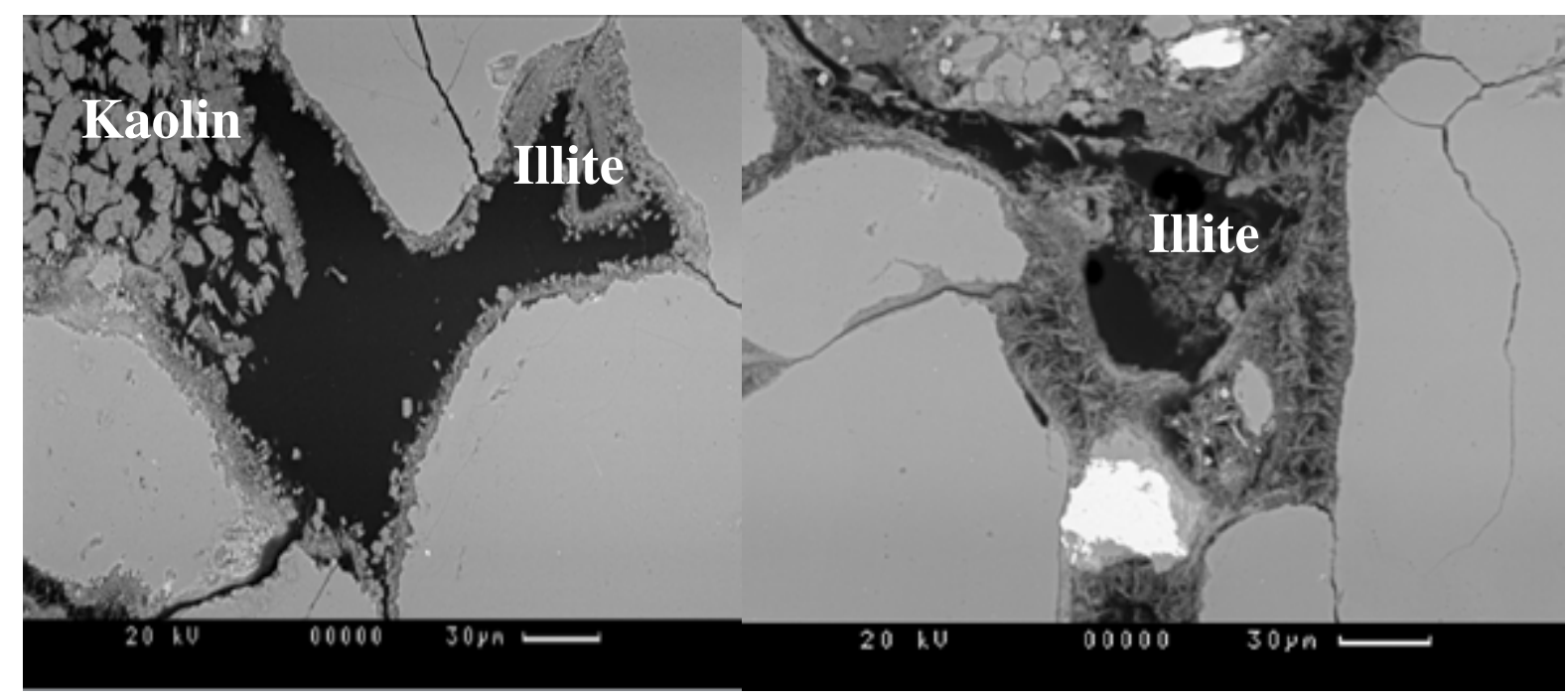

(b)

(C)

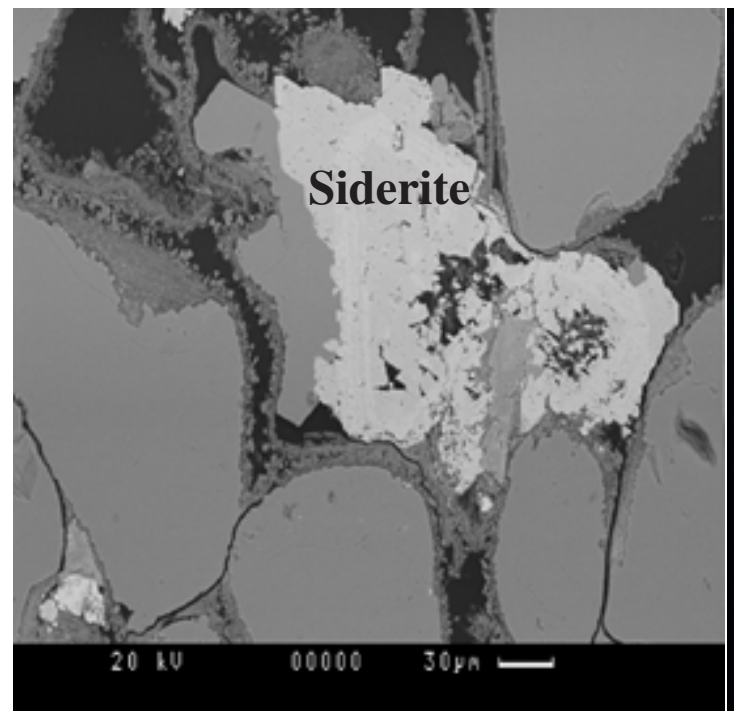

(b)

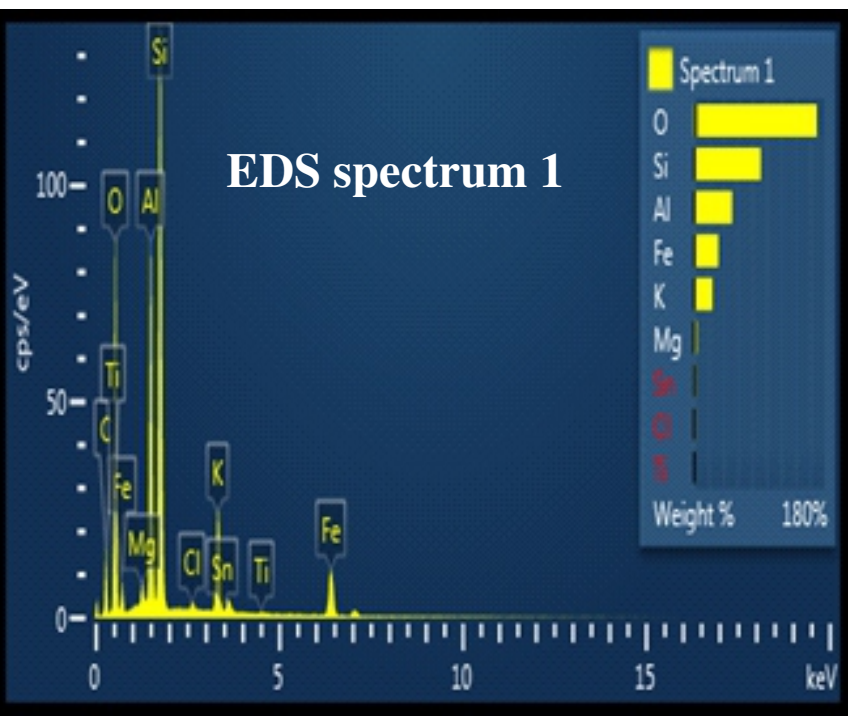

(d)

Fig.4. SEM images (a-c) and EDS (d) of illite as a grain coating mineral. Chemical formula for illite is given as $(\mathrm{K}, \mathrm{H} 3 \mathrm{O})(\mathrm{Al}, \mathrm{Mg}, \mathrm{Fe}) 2(\mathrm{Si}, \mathrm{Al}) 4 \mathrm{O} 10[(\mathrm{OH}) 2,(\mathrm{H} 2 \mathrm{O})]$ 


\section{Microstructural and mineralogical rock typing; summary bar chart}

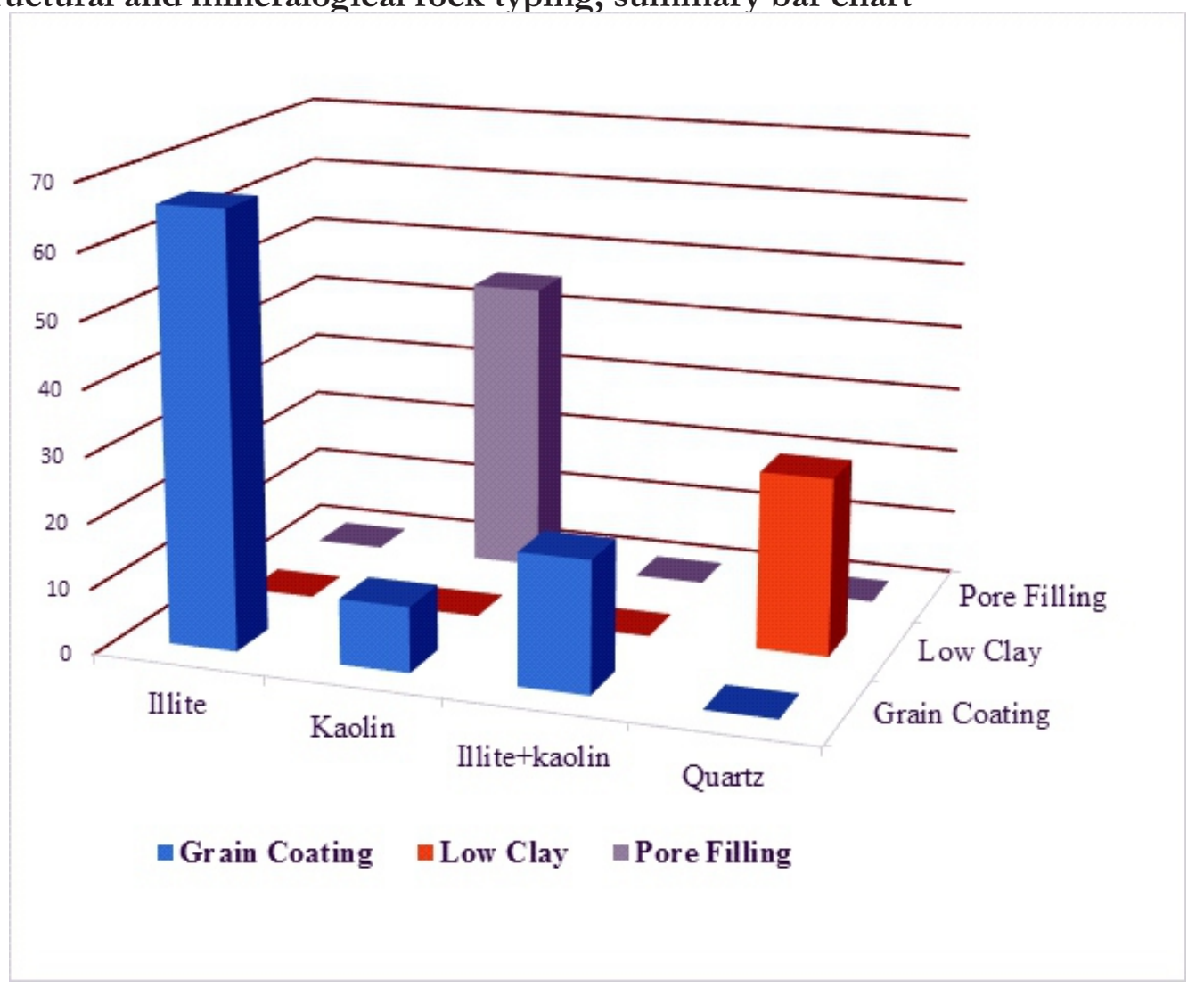

Fig.5. Bar chart showing the relationship between microstructural rock types and the prevailing authigenic clay

The microstructural rock types appear to have a strong relationship with the prevailing authigenic clay mineralogy and so are controlled by diagenesis. Samples identified as grain coating are mostly dominated by illite followed by the coexistence of illite and kaolin and lastly by kaolin. Samples identified as pore filling are mostly dominated by kaolin. Samples identified as having a low clay content are mainly composed of quartz (Fig.5)

\section{Linear regression analysis}

This study attempted to find a link between the microstructures and the various poroperm trends. The observed behaviour of the $>200$ analysed samples suggest that the clay content and morphology control the reservoir permeability variation as a function of porosity in tight gas reservoirs. The three established microstructural rocktypes established (low clay, pore filling and grain coating) occupy different but overlapping positions on poroperm cross plots (Fig.6) 

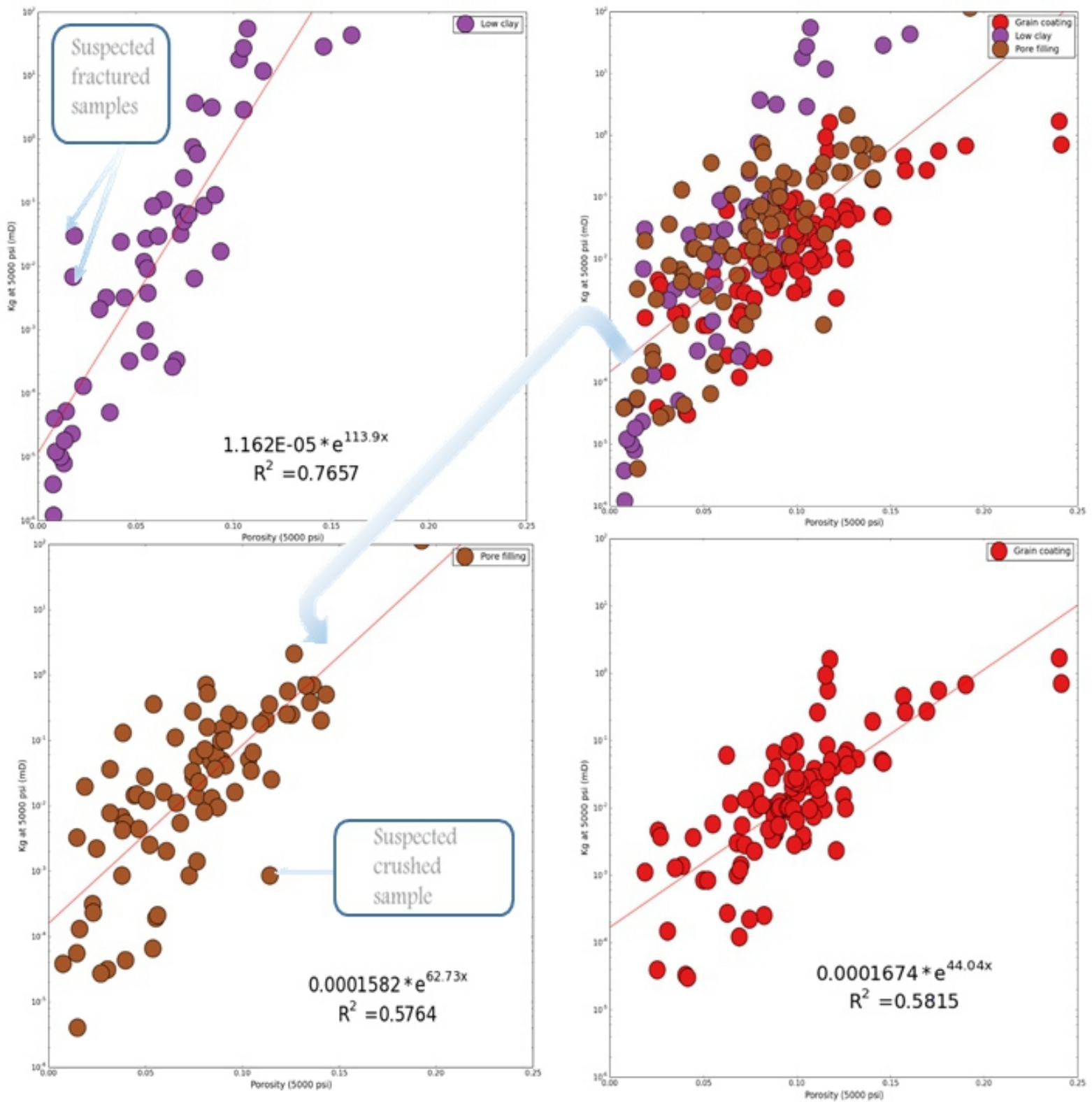

Figure 6. Poroperm plots of three microstructural rock-types: (a) Low clay (b) Pore filling (c) Grain coating

There is an obvious reservoir quality variation from one rock type to another as shown by the rock type based poroperm cross plots. The regression line bending towards the right as we move from low clay to pore filling and finally to grain coating formation confirms the following: (i) there is no uniformity on how permeability varies as a function of porosity for the three established microstructural rock types (ii) the impact of illite which mostly coats the grains on reservoir quality is more intense than that of kaolin which mostly fills the pores.(iii) permeability predictions from poroperm are dragged towards the mid qualities when microstructural rock typing is ignored, therefore leading to exclusion of extreme qualities 


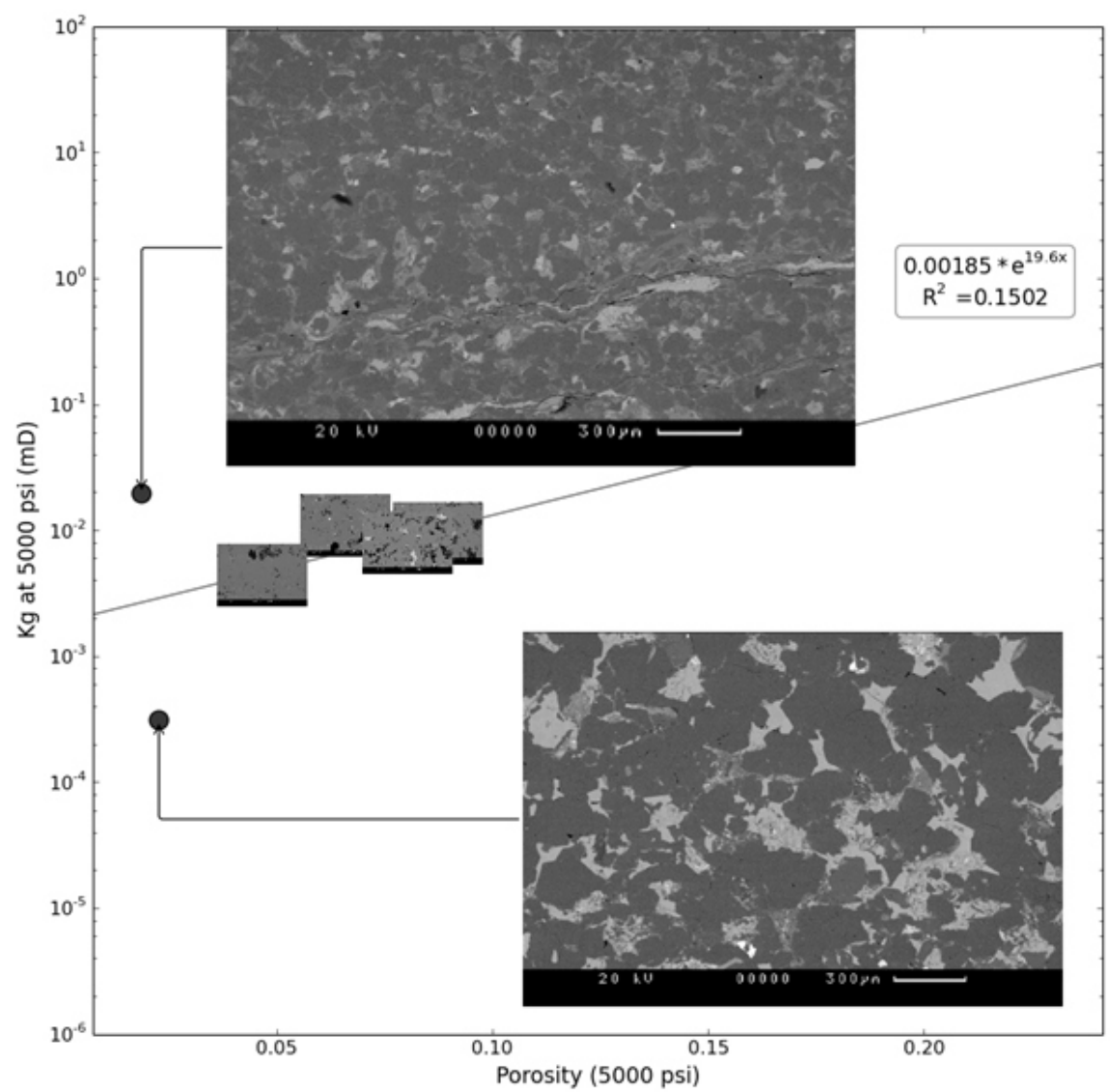

Fig 7: SEM image plot: The sample points replaced with SEM images using a data visualisation software (PETMiner) improves identification of key controls on properties (e.g. permeability). The datapoint that plotted above the regression line was identified by the SEM image plot as a fractured sample. The position of the sample on the poroperm plot (low porosity but high permeability) suggest that its quality index cannot be explained by the basic pore network model.

The point information from this plot (Fig. 7) further reveals that fracture porosity representing the less tortuous flow channel controls permeability more than the intergranular passageway at low porosity zones of a fractured reservoir. Excluding this fractured sample from the plot improved the goodness of fit by a significant amount $(\sim 0.63)$ (Fig.8). Fracture flow points are best treated as outliers during linear regression analysis, especially when they are poorly represented in the reservoir.

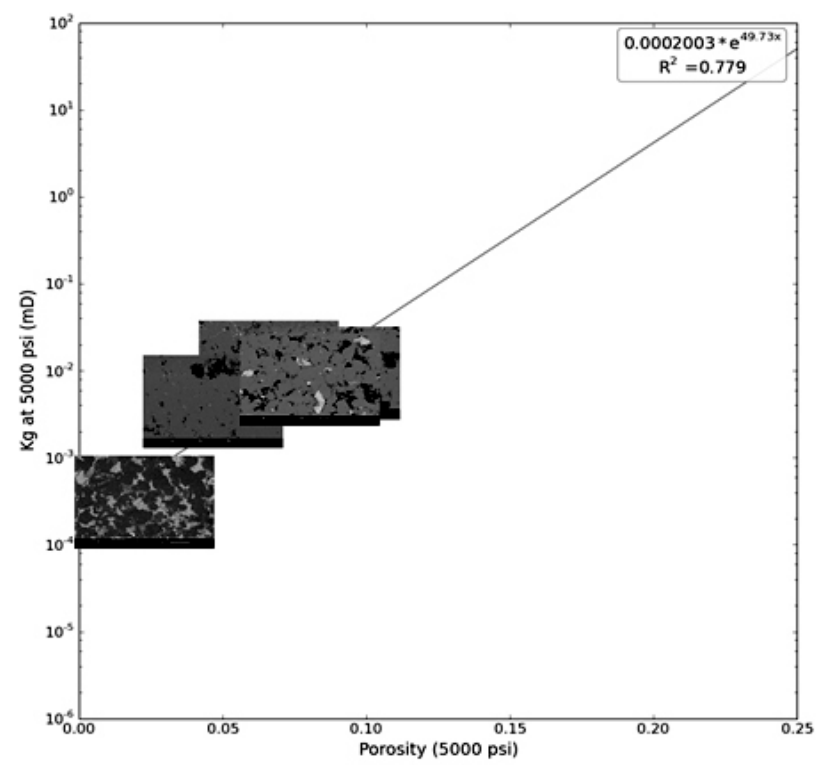

Fig 8. SEM image plot 
Investigated outliers excluded from linear fit. Excluding fractured and crushed sample points from linear fit improved the goodness of fit by:

$(\sim 0.05)$ for low clay rock type

$(\sim 0.06)$ for pore filling rock type

$(\sim 0.02)$ grain coating rock type

\section{Continuous permeability estimation using microstructural rock type-based poroperm functions.}

Exponential functions were fitted to porositypermeability data for each rock type and then applied to the porosity values from wire-line log data (Fig 9) to derive continuous permeability in the following ways;

Step 1: Identify the microstructural rock type of an interval of interest (Track 6$)$.

Step 2: Calibrate log porosity with core data to avoid error propagation (Track 7).

Step 3: Apply suitable exponential function to porosity values from wire-line $\log$ data to derive continuous permeability (Track 8).

Step 4: Compare the estimated permeability curve with core or NMR permeability depending on which is available (Track 9).

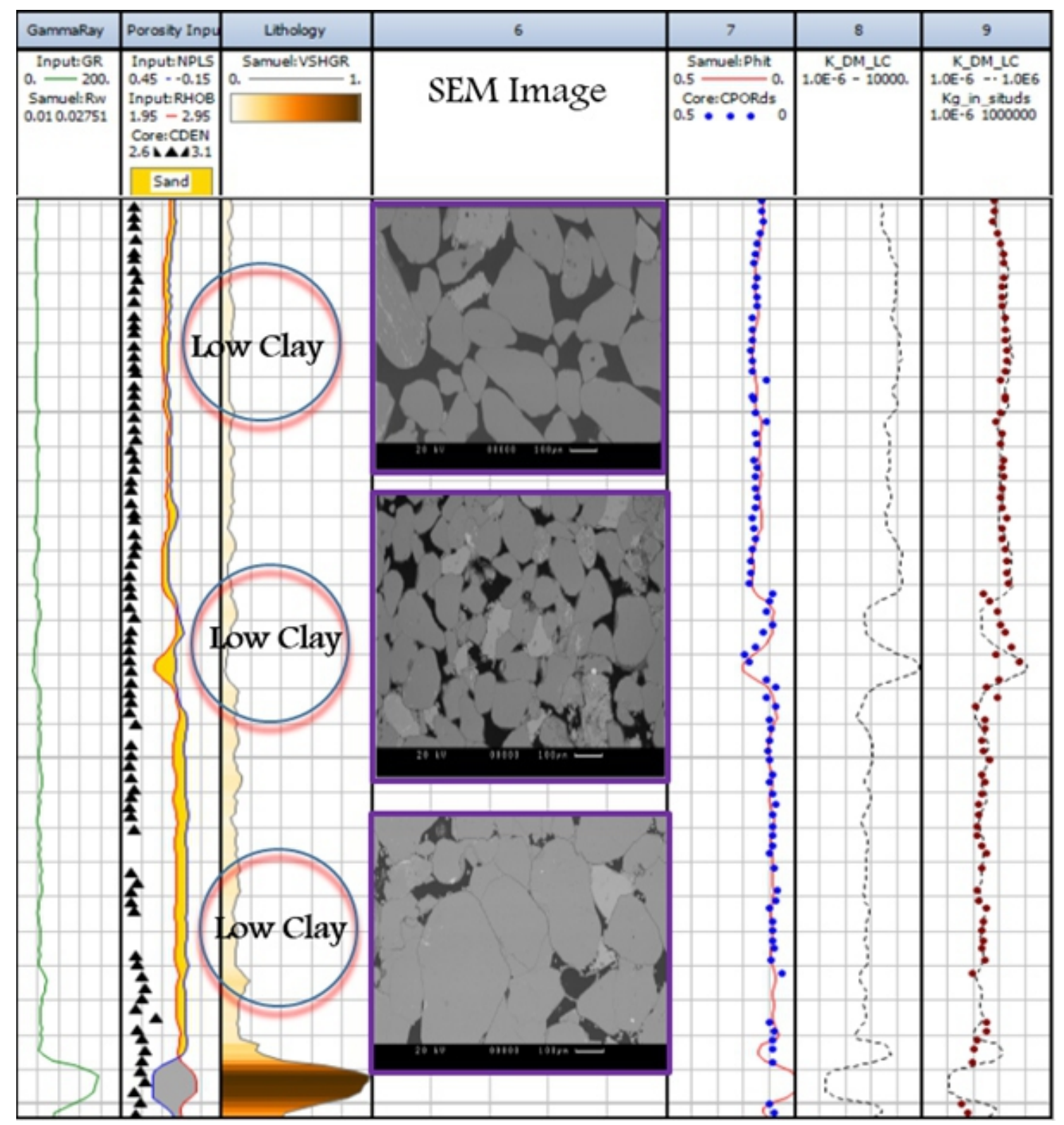

Fig.9: Log capture showing the estimated continuous permeability matching well with the core permeability values. For the sake of statistical validation, more than three SEM images are required to assign a rock type to an interval. The display of just three SEM images in the $4^{\text {th }}$ track is for better visualisation and explanation purposes. 


\section{Unique Flow Units}

The 'Unique Flow Units (UFU)' as defined in this study are zones whose core permeabilities stand out and anomalously differ by large extent from the continuous $\log$ of permeability that was predicted by the established poroperm function. It is believed that such small interval that shows departure from the predicted permeability has a different poroperm relationship or pore geometry that could not be not be honoured by the applied function. Probable causes of unique flow units are :i) Anomalous change in clay morphology within a relatively homogeneous reservoir zone. (ii)Micro fractures.

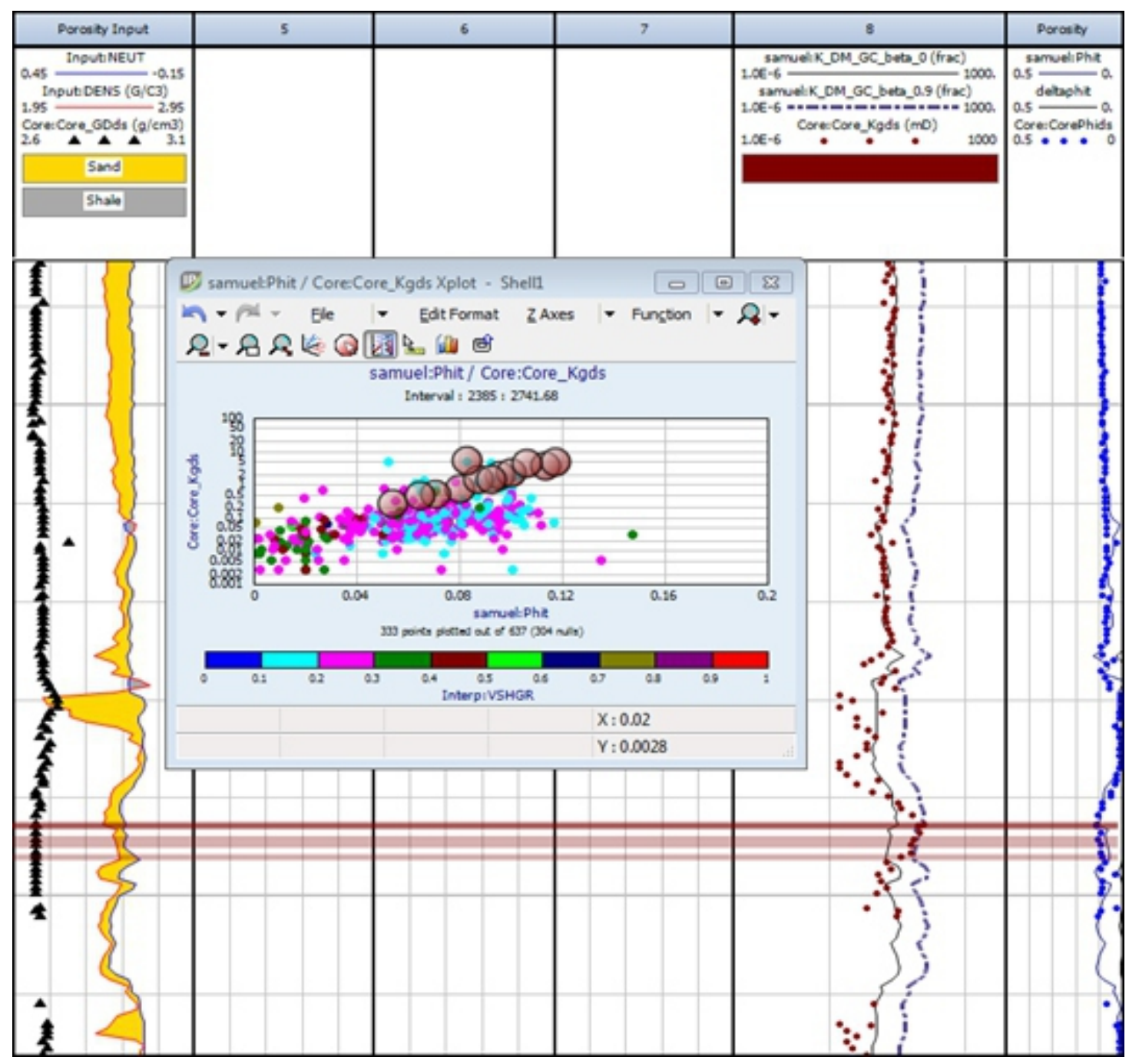

Fig 10.Log capture showing the unique flow unit. The bigger-object data points plotted uniquely above most of the data points. It was highlighted on the cross plot and confirmed automatically on the log plot using the "highlight object function" of interactive petrophysics software.

\section{Determination of shale distribution: The Thomas Stieber-Juhasz Model}

Thomas Stieber-Juhasz model was used to determine the distribution of shale within a shaly sand formation by comparing the total volume of shale with the total porosity. The theory behind this model lies in defining the elements of the clean sand formation which are 'replaced' by the shale. If the rock typing technique is based on shale distribution within rock matrix, then it is possible to have three rock types (dispersed, laminated and structural). This study investigated the Thomas-Stieber-Juhasz model and its limitation in rock typing tight gas sandstone reservoirs. 


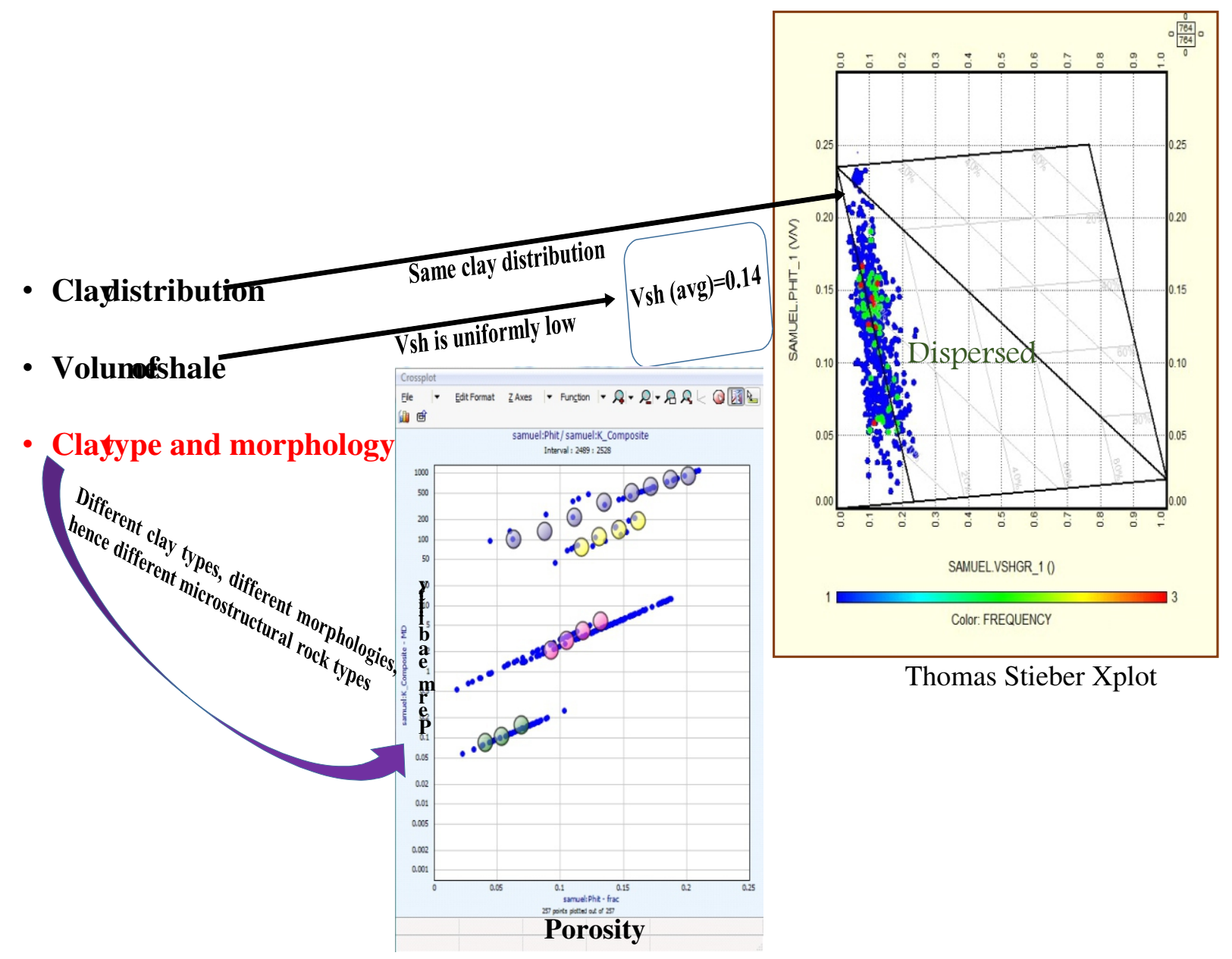

Figure 11.Significance of microstructural rock typing in formation evaluation. Whether or not clays will significantly impact porosity or permeability of a reservoir depends on the following factors; (i) clay distribution (ii) volume of shale, (iii) clay type and morphology.

An interval with a uniformly low volume of shale has all its data points plotted along the dispersed shale distribution line (Fig.11). However, the poroperm plot reveals three distinct trends that can be related to the three corresponding microstructural rock types in the order of increasing reservoir quality. The slight separation observed between data points in the uppermost trend is due to minor difference in reservoir quality index between the affected samples despite they are identified with the same microstructural rock type. This scenario was mostly identified at the low clay intervals in this study. Dispersed clay which evolve from alteration and precipitation of clay minerals can either coat the rock matrix or partially fill the porespaces (Tiab et al.,2004).A single rock type could have been assigned to this particular interval in error, if the rock typing was based on Thomas Stieber shale distribution model or if the facie selection criteria was based on volume of shale cut off.

This observation corroborates the essence of understanding the petrological controls on permeability-porosity relationship before selecting a rock typing technique for poroperm linear regression analysis. According to Teh et.al. (2012), the value of petrophysical classifier can vary significantly within a single lithofacies. The constraint of Thomas Stieber model in grouping data into rock types is its inability to identify or account for variation in microstructural rock property as data of different microstructural rock type plot along a single shale distribution line. The use of shale distribution-based poroperm functions in some tight gas reservoirs oversimplified the predicted permeability (Fig.11). 


\section{CONCLUSION}

Continuous permeability that honours mineralogical variation can be obtained by the use of microstructural rock typing. The effectiveness and predictive accuracy of the poroperm transform functions depend on the rock typing technique employed in discriminating the rock formation. Prior to doing this, it is recommended to have a good understanding of petrological controls on permeability by studying the microscopic details such as the clay morphology of the reservoir. For formations that have been hugely impacted by digenesis, the controls on permeability may not be obvious on some macroscopic scales such as conventional log responses. To base the rock type selection criteria on macroscopic parameters may lead to exclusionof extreme reservoir qualities and may never be honoured in the entire reservoir characterisation process. The revealing situation encountered in this study could be of great economic advantage, where there is a substantial relationship between the microstructural and the mineralogical rock types. Mineralogical descriptions from drill cuttings could be translated into microstructural rock types.

We are in the petroleum industry age, where much attention is to be given to understanding reservoir qualities in order to improve reserve estimation and production forecast. It is also clear that the job of the petrophysicist is to provide these qualities in quantitative terms, which makes the role of a petrophysicist a very important link in the chain of petroleum experts.

Any error at the stage of formation evaluation has a corresponding misleading influence on the petroleum project economics. It will be recommended that more microstructural description should be incorporated into day- today petrophysical analysis.

\section{ACKNOWLEDGEMENTS}

This paper is dedicated to the Almighty God. This study was possible within the available time due to the robust compilation of data recorded over the past three years by the Wolfson Laboratory, University of Leeds. Special thanks for the fruitful discussions with Professor Quentin Fisher and
Dr. Carlos Grattoni from University of Leeds during the course of the study.

We also acknowledge Dr. Dave Harrison from University of Leeds for his help on how to use the Pet Miner software for data visualisation.

\section{REFERENCES}

Ali, S.A, Clark, W. J., Moore, W. R. and Dribus, J. R. 2010. 'Diagenesis and Reservoir Quality', Oilfield Review 22(2): 14-27. doi: 10.1080/10916466.2012.742542.

Archer J.S;Wall C.G. 1986. 'Petroleum Engineering Principles and Practice', Springer pp. 1-11. doi: 10.1007/978-94010-9601-0.

Byrnes, A. P. 1996. 'Reservoir Characteristics of Low-Permeability Sandstones in the Rocky Mountains'.

Byrnes, A. P. 2009. 'Lithofacies and Petrophysical Properties of Mesaverde Tight-Gas Sandstones in Western U. S. Basins: a short course', (June).

Eberl, D. D. 1993. 'Three Zones for Illite Formation during Burial Diagenesis and Metamorphism', Clays and Clay Minerals. doi: 10.1346/CCMN.1993.0410103.

Huang, K. 2012. 'Authigenic Illite in the Sandstone Reservoirs of Taiyuan Formation, Northeast Ordos Basin*'.

Joanna M., A. and Lander, R. H. 2010. 'Sandstone reservoir quality prediction: The state of the art', AAPG Bulletin. doi: 10.1306/intro060110.

John W. Neasham 1977. "The Morphology of Dispersed Clay in Sandstone Reservoirs and its Effect on Sandstone Shaliness, Pore Space and Fluid Flow Properties'.

Leder, F. and Park, W. 1986. 'Porosity Reduction in Sandstone by Quartz Overgrowth', American Association of Petroleum Geologists Bulletin 70(11): 1713-1728.

McPhee, C., Reed, J. and Zubizarreta, I. 2015. 'Best Practice in Coring and Core Analysis', in Developments in Petroleum Science. doi: 10.1016/B978-0-444-63533-4.00001-9.

Teh, W. J., Willhite, G. P. and Doveton, J. H. 2012. 'Improved Reservoir Characterization using Petrophysical Classifiers within', Eighteenth SPE Improved Oil Recovery Symposium pp. 1-13. doi: 10.2118/154341- 
ms.

Thomas, E.C. and Stieber, S.J. 1975. "The Distribution of Shale in Sandstones and its Effect upon

Porosity", presented at the SPWLA annual symposium.

Tiab, D., \& Donaldson, E. C. 2004. 'Petrophysics: Theory and Practice of Measuring Reservoir Rock and Fluid Transport Properties.Boston:Gulf professional Pub.', p. 2004.

Walder, J. and Nur, A. 1984. 'Porosity Reduction and Crustal Pore Pressure Development', Journal of Geophysical Research 89(B13): 11539. doi: 10.1029/JB089iB13p11539.
Walsh, J. B. and Brace, W. F. 1984. 'The Effect of Pressure on Porosity and the TransportProperties of Rock', Journal of Geophysical Research 89(B11): 9425-9431. doi: 10.1029/JB089iB11p09425.

Worthington, P. 2011. 'The Petrophysics of Problematic Reservoirs', Journal of Petroleum Technology 63(12): 88-97. doi: 10.2118/144688-MS.

Xie, J. 2008. 'Improved Permeability Prediction using Multivariate Analysis Methods Available at oaktrust.library.tamu. edu/bitstream/handle/1969.1/ETDTAMU.../Xie-Thesis.pdf $\% 0$ A.

\section{APPENDIX}

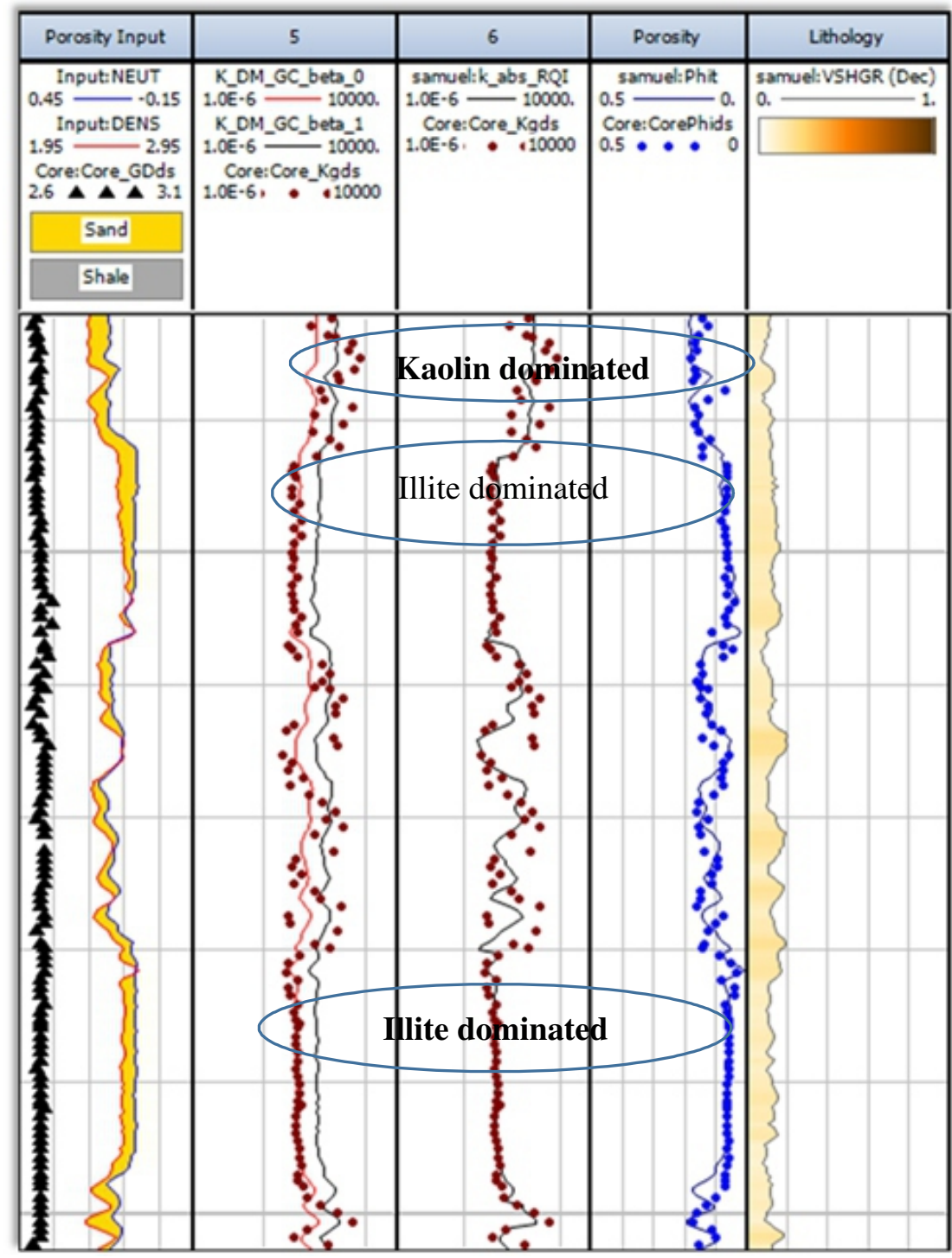

Figure 12: Log capture showing the effect of mineralogy on the permeability derived from porosity (Track 3) 
Figure 12: Log capture showing the effect of mineralogy on the permeability derived from porosity (Track 3)

\begin{tabular}{|c|c|c|c|c|c|}
\hline Samples & Clay Mineralogy & Grain Density & rosity & In situ Porosity & In situ Permeability \\
\hline $\mathrm{S} 1$ & Low kaolin and illite & 2.66 & 0.12 & 0.10 & 17.90 \\
\hline $\mathrm{S} 2$ & Low kaolin and illite & 2.65 & 0.12 & 0.11 & 27.00 \\
\hline S3 & Low kaolin and illite & 2.66 & 0.18 & 0.16 & 42.90 \\
\hline S4 & Low kaolin and illite & 2.67 & 0.13 & 0.11 & 0.26 \\
\hline S5 & Low kaolin and illite & 2.66 & 0.13 & 0.12 & 1.59 \\
\hline S6 & Low kaolin and illite & 2.67 & 0.11 & 0.10 & 0.09 \\
\hline S7 & Low kaolin and illite & 2.64 & 0.12 & 0.11 & 0.07 \\
\hline S8 & Low kaolin and illite & 2.65 & 0.13 & 0.12 & 11.70 \\
\hline S9 & Low kaolin and illite & 2.64 & 0.09 & 0.08 & 3.68 \\
\hline S10 & Low kaolin and illite & 2.68 & 0.07 & 0.06 & 0.09 \\
\hline S11 & Kaolin dominated & 2.64 & 0.20 & 0.18 & 0.55 \\
\hline S12 & Kaolin dominated & 2.64 & 0.19 & 0.17 & 0.27 \\
\hline S13 & Kaolin dominated & 2.65 & 0.26 & 0.24 & 1.67 \\
\hline S14 & Kaolin dominated & 2.66 & 0.26 & 0.24 & 0.70 \\
\hline S15 & Kaolin dominated & 2.70 & 0.09 & 0.07 & 0.27 \\
\hline S16 & Kaolin dominated & 2.65 & 0.11 & 0.10 & 0.20 \\
\hline S17 & Kaolin dominated & 2.67 & 0.14 & 0.13 & 0.25 \\
\hline S18 & Kaolin dominated & 2.68 & 0.15 & 0.14 & 0.69 \\
\hline S19 & Kaolin dominated & 2.68 & 0.15 & 0.13 & 0.69 \\
\hline $\mathrm{S} 20$ & Kaolin dominated & 2.65 & 0.14 & 0.12 & 0.56 \\
\hline $\mathrm{S} 21$ & Kaolin dominated & 2.70 & 0.14 & 0.12 & 0.25 \\
\hline $\mathrm{S} 22$ & Kaolin dominated & 2.68 & 0.15 & 0.13 & 0.38 \\
\hline $\mathrm{S} 23$ & Illite dominated & 2.68 & 0.12 & 0.11 & 0.01 \\
\hline S24 & Illite dominated & 2.68 & 0.10 & 0.09 & 0.01 \\
\hline $\mathrm{S} 25$ & Illite dominated & 2.68 & 0.13 & 0.11 & 0.01 \\
\hline S26 & Illite dominated & 2.69 & 0.10 & 0.09 & 0.01 \\
\hline $\mathrm{S} 27$ & Illite dominated & 2.64 & 0.10 & 0.09 & 0.15 \\
\hline $\mathrm{S} 28$ & Illite dominated & 2.67 & 0.11 & 0.10 & 0.01 \\
\hline S29 & Illite dominated & 2.68 & 0.07 & 0.06 & 0.02 \\
\hline S30 & Illite dominated & 2.64 & 0.06 & 0.05 & 0.01 \\
\hline S31 & Illite dominated & 2.65 & 0.09 & 0.08 & 0.07 \\
\hline S32 & Illite dominated & 2.65 & 0.10 & 0.08 & 0.01 \\
\hline S33 & Illite dominated & 2.65 & 0.09 & 0.08 & 0.01 \\
\hline S34 & Illite dominated & 2.64 & 0.11 & 0.09 & 0.02 \\
\hline S35 & Illite dominated & 2.68 & 0.12 & 0.11 & 0.0 \\
\hline
\end{tabular}


Table 3.QXRD information of some samples selected based on dominant clay mineralogy.

\begin{tabular}{|c|c|c|c|c|c|c|c|c|c|c|c|c|c|c|}
\hline \multirow{2}{*}{ Samples } & \multicolumn{14}{|c|}{ Quantitative X-ray Diffraction Information } \\
\hline & Quartz & Albite & Microclin & alcite & Dolomite & Magnesite I & Mica & Illite & Kaolin & Chlorite I & Pyrite $S$ & lerite & Barite & hydrit \\
\hline$S 1$ & 82.01 & 2.51 & 3.67 & 0.00 & 2.75 & 0.00 & 5.81 & 0.45 & 0.00 & 2.00 & 0.00 & 1.13 & 0.00 & 0.00 \\
\hline S2 & 82.58 & 2.72 & 3.72 & 0.00 & 4.10 & 0.00 & 3.70 & 1.45 & 0.00 & 4.00 & 0.00 & 0.88 & 0.00 & 0.00 \\
\hline S3 & 82.80 & 2.99 & 4.82 & 0.00 & 3.38 & 0.00 & 4.18 & 2.22 & 0.00 & 2.01 & 0.00 & 0.58 & 0.00 & 0.00 \\
\hline S4 & 73.70 & 5.69 & 5.97 & 0.00 & 4.67 & 0.00 & 5.34 & 4.37 & 0.00 & 2.80 & 0.00 & 0.81 & 0.00 & 0.00 \\
\hline S5 & 71.53 & 4.97 & 4.31 & 0.00 & 5.17 & 0.00 & 4.14 & 4.71 & 0.00 & 3.30 & 0.00 & 0.83 & 0.00 & 0.00 \\
\hline S6 & 76.10 & 6.20 & 6.50 & 0.20 & 4.70 & 0.00 & 2.60 & 2.90 & 0.00 & 0.00 & 0.00 & 0.00 & 0.00 & 0.40 \\
\hline S7 & 84.90 & 0.00 & 6.50 & 0.00 & 0.00 & 0.00 & 1.30 & 5.60 & 1.70 & 0.00 & 0.00 & 0.00 & 0.00 & 0.00 \\
\hline S8 & 94.90 & 2.20 & 2.40 & 0.00 & 0.30 & 0.00 & 0.00 & 0.00 & 0.00 & 0.00 & 0.20 & 0.00 & 0.00 & 0.00 \\
\hline S9 & 90.10 & 0.40 & 0.00 & 0.50 & 0.60 & 0.00 & 1.00 & 1.30 & 3.10 & 0.90 & 0.20 & 0.60 & 1.10 & 0.10 \\
\hline S10 & 85.40 & 0.40 & 0.00 & 0.40 & 3.90 & 0.00 & 0.20 & 2.10 & 3.60 & 0.50 & 0.30 & 1.10 & 0.30 & 1.90 \\
\hline S11 & 77.17 & 2.86 & 5.75 & 0.00 & 1.01 & 0.00 & 2.48 & 1.48 & 11.52 & 0.00 & 0.00 & 0.87 & 0.00 & 0.00 \\
\hline S12 & 78.86 & 0.00 & 5.36 & 0.00 & 3.10 & 0.00 & 2.56 & 0.96 & 10.19 & 0.00 & 0.00 & 0.34 & 0.00 & 0.00 \\
\hline S13 & 73.02 & 0.00 & 5.82 & 0.00 & 2.20 & 0.00 & 3.48 & 2.64 & 10.56 & 0.00 & 0.00 & 0.43 & 0.00 & 0.00 \\
\hline S14 & 77.14 & 0.00 & 5.50 & 0.00 & 2.30 & 0.00 & 5.35 & 0.00 & 11.36 & 0.00 & 0.74 & 0.00 & 0.00 & 0.00 \\
\hline S15 & 73.22 & 2.00 & 1.46 & 0.00 & 5.78 & 0.00 & 8.18 & 0.00 & 6.41 & 0.00 & 0.00 & 4.80 & 0.00 & 0.00 \\
\hline S16 & 81.40 & 2.20 & 3.80 & 0.00 & 0.00 & 0.00 & 1.00 & 1.90 & 6.80 & 1.30 & 0.00 & 0.00 & 0.00 & 0.00 \\
\hline S17 & 85.60 & 0.40 & 2.30 & 0.00 & 0.10 & 0.00 & 0.50 & 0.80 & 5.40 & 3.50 & 0.00 & 0.00 & 0.00 & 0.00 \\
\hline S18 & 78.38 & 2.47 & 5.02 & 0.00 & 0.00 & 0.00 & 2.55 & 0.00 & 12.58 & 2.55 & 0.00 & 0.00 & 0.00 & 0.00 \\
\hline S19 & 78.38 & 2.47 & 5.02 & 0.00 & 0.00 & 0.00 & 2.55 & 0.00 & 12.58 & 2.55 & 0.00 & 0.00 & 0.00 & 0.00 \\
\hline S20 & 68.20 & 0.70 & 6.84 & 0.00 & 0.00 & 0.00 & 1.80 & 0.00 & 17.06 & 3.55 & 0.36 & 0.00 & 0.00 & 0.00 \\
\hline S21 & 68.20 & 0.70 & 6.84 & 0.00 & 0.00 & 0.00 & 1.80 & 0.00 & $\mid 17.06$ & 3.55 & 0.36 & 0.00 & 0.00 & 0.00 \\
\hline S22 & 80.40 & 0.00 & 0.00 & 0.00 & 3.10 & 0.00 & 5.50 & 2.60 & 8.70 & 0.00 & 0.40 & 1.30 & 0.00 & 0.00 \\
\hline S23 & 66.54 & 8.94 & 0.00 & $\overline{0.00}$ & 3.92 & 0.00 & 0.00 & \begin{tabular}{|l|}
17.47 \\
\end{tabular} & 0.00 & 2.18 & 0.00 & 1.07 & 0.00 & 0.00 \\
\hline S24 & 71.76 & 8.80 & 0.00 & 0.00 & 4.58 & 0.00 & 0.00 & 15.31 & 0.00 & 0.00 & 0.00 & 1.45 & 0.00 & 0.00 \\
\hline S25 & 68.47 & 9.39 & 0.00 & 0.00 & 4.06 & 0.00 & 0.00 & 15.70 & 0.00 & 0.00 & 0.00 & 1.29 & 0.00 & 0.00 \\
\hline S26 & 70.86 & 8.17 & 0.00 & 0.00 & 4.26 & 0.00 & 0.00 & 15.15 & 0.00 & 0.00 & 0.00 & 1.81 & 0.00 & 0.00 \\
\hline S27 & 73.10 & 4.80 & 8.60 & 0.00 & 0.20 & 0.00 & 1.40 & 9.50 & 1.00 & 0.00 & 0.90 & 0.00 & 0.00 & 0.60 \\
\hline S28 & 80.30 & 1.60 & 5.00 & 0.00 & 4.60 & 0.00 & 2.60 & 5.10 & 0.00 & 0.00 & 0.00 & 0.00 & 0.00 & 0.00 \\
\hline S29 & 70.80 & 6.20 & 8.10 & 0.00 & 0.20 & 0.00 & 1.50 & 8.00 & 1.40 & 0.00 & 2.60 & 0.00 & 0.00 & 0.20 \\
\hline S30 & 62.10 & 6.80 & 8.00 & 0.00 & 0.10 & 0.00 & 2.60 & 13.20 & 3.90 & 0.30 & 0.00 & 0.20 & 0.00 & 0.00 \\
\hline S31 & 69.10 & 5.10 & 9.30 & 0.00 & 0.00 & 0.00 & 2.30 & 10.60 & 1.60 & 0.00 & 1.50 & 0.00 & 0.00 & 0.00 \\
\hline S32 & 69.30 & 6.30 & 10.20 & 0.00 & 2.10 & 0.00 & 2.70 & 7.70 & 0.50 & 0.00 & 1.20 & 0.00 & 0.00 & 0.00 \\
\hline S33 & 70.20 & 6.20 & 10.20 & 0.00 & 1.80 & 0.00 & 0.00 & 8.70 & 1.50 & 0.00 & 1.40 & 0.00 & 0.00 & 0.00 \\
\hline S34 & 76.90 & 4.60 & 8.20 & 0.00 & 0.50 & 0.00 & 2.30 & 6.60 & 0.00 & 0.00 & 0.90 & 0.00 & 0.00 & 0.00 \\
\hline S35 & 81.00 & 1.20 & 1.50 & 0.40 & 2.60 & 0.00 & 1.30 & 8.90 & 0.00 & 0.70 & 0.00 & 0.90 & 0.00 & 0.00 \\
\hline
\end{tabular}

